\title{
Knowledge mobilization in healthcare organizations: a view from the resource-based view of the firm
}

\author{
Ewan Ferlie $^{1^{*}}$, Tessa Crilly², Ashok Jashapara ${ }^{3}$, Susan Trenholm ${ }^{4}$, Anna Peckham ${ }^{5}$, Graeme Currie $^{6}$
}

Abstract

This short literature review argues that the Resource-Based View (RBV) school of strategic management has recently become of increased interest to scholars of healthcare organizations. RBV links well to the broader interest in more effective Knowledge Mobilization (KM) in healthcare. The paper outlines and discusses key concepts, texts and authors from the RBV tradition and gives recent examples of how RBV concepts have been applied fruitfully to healthcare settings. It concludes by setting out a future research agenda.

Keywords: Resource-Based View (RBV), Knowledge Mobilization (KM), Healthcare Organizations

Copyright: @ 2015 by Kerman University of Medical Sciences

Citation: Ferlie E, Crilly T, Jashapara A, Trenholm S, Peckham A, Currie G. Knowledge mobilization in healthcare organizations: a view from the resource-based view of the firm. Int J Health Policy Manag 2015; 4: 127-130. doi: $10.15171 /$ ijhpm.2015.35

\author{
Article History: \\ Received: 29 November 2014 \\ Accepted: 21 January 2015 \\ ePublished: 20 February 2015
}

*Correspondence to:

Ewan Ferlie

Email: ewan.ferlie@kcl.ac.uk

\section{Introduction}

Why is there increased interest in the academic health management literature in accessing the Resource-Based View (RBV) school of strategic management $(1,2)$ ? Such interest might prima facie be thought curious for two reasons. Firstly, health management research often tends towards an empiricist mode and is suspicious of abstract theory. As a counterbalancing tendency, however, researchers working in a critical realist position are seeking to develop candidate programme theories (1) to explain empirical phenomena, such as the variable fate within healthcare organizations of large scale quality improvement efforts. Secondly, it is often argued that theories developed for private sector firms may not travel well into public sector healthcare settings, or at least require major adaptation. We will argue here that RBV should now be of interest to health management researchers and organizations, although it may still need to be customised.

In this short paper, firstly, we consider developments in the health policy domain which make RBV of enhanced interest. Then we outline core concepts in RBV theory and give brief healthcare examples. Finally, we make a case for further use of RBV in future research and consider some managerial implications for healthcare settings.

The changing health policy context: Knowledge Mobilization (KM), wealth as well as health

UK health policy has become increasingly interested $(3,4)$ in diffusing promising healthcare innovations at greater pace and scale. This goal in turn fundamentally depends on developing a corporate Knowledge Mobilization (KM) capacity so health organizations and even health systems can move 'from knowing to doing' speedily. This policy stream is interested in new goals of wealth creation as well as traditional ones of health improvement: it seeks to support the faster spinning out of new products (e.g. new drugs, new devices, apps) in a hyper competitive and fast moving knowledge-based economy, where the healthcare and bio pharma sectors play a strategic economic role. It seeks to link traditional public sector healthcare organizations with private firms in a medical/innovation complex in regionally based innovation systems.

Researchers in other countries share their UK counterparts' interest in enhancing knowledge diffusion within and across healthcare organizations and systems. In the US, researchers identified a pressing need for improved clinical research translation and for evidence that the vast public investment in healthcare is bearing fruit $(5,6)$. The mission of the Department of Veterans' Affairs Quality Enhancement Research Initiative (QUERI) is to have clinical practice needs inform the healthcare research agenda in order speed the spread of innovations and, ultimately, to enhance health outcomes (7). The scale, scope and significance of QUERI's work has been acknowledged internationally (8). The American not-for-profit Institute for Healthcare Improvement has among its goals the spread of proven patient safety practices across America, with the promotion of the "science of implementation" as one of its objectives (9). It has also documented the challenges and frustrations associated with diffusing best practices and innovations within the US healthcare system (10).

In Canada, the importance, role and necessity of so-called "knowledge brokering" within the healthcare system has been acknowledged (11), with knowledge brokerage demonstration projects funded at six different sites (12). The Canada Health Services Research Foundation was established "to facilitate evidence-based decision-making in Canada's health sector" (13), while the publicly supported Institute of Health Services and Policy Research has Knowledge Translation (KT) with the goal of improving the health of Canadians at the heart of its mission (14). Graham and Tetroe (15) have 
analyzed the significance of KT to the Canadian healthcare research community, including the Canadian government. Similarly, Dutch policy-makers aim to make interactions between healthcare researchers and practitioners more fruitful, responding, in part, with the creation of Academic Collaborative Centres for Public Health (16).

How should we approach this policy stream analytically? One could build on the earlier healthcare based literature on the Evidence-Based Medicine (EBM) movement which raised issues of patchy implementation, change resistance and difficulties in KT [see Straus et al. (17), 2013's overview]. However, these issues were often considered in this literature at the micro level of the clinical team or even individual. This tradition emphasises the design of $\mathrm{KT}$ interventions to shift behaviours, searching for levers for and barriers to evidencebased change.

By contrast, KM policy operates at a macro organizational/ systemic level. It is less concerned with specific interventions than with building underpinning core competences to facilitate repeated and speedy innovation diffusion across the healthcare field. It seeks the timely spinning out of new economic products from the healthcare sector as well as EBM implementation, bringing in a concern for new economic actors (e.g. bio pharma; high tech start ups) in more conventional firms. We argue RBV can be usefully brought in to help conceptualise these distinctive arenas. While RBV was originally developed in private sector settings, there are now RBV-based studies from healthcare field.

We here draw on our recent structured literature review (18) considering RBV's application to KM in healthcare organizations. Given space constraints, the search and analysis strategy is not outlined in detail but interested readers can refer to the final report (18), uploaded onto UK NIHR's website. We now introduce major RBV ideas and give brief examples from healthcare settings.

\section{Resource-Based View (RBV) of the firm}

$\mathrm{RBV}$ (originally developed in private sector firms) is a major branch of the strategic management literature. Pioneering authors such as Penrose (19) and Wernerfelt (20) examined the distinctive profile of the individual firm rather than taking a more conventional focus on industry structure, its profit margins and barriers to market entry or exit. RBV sees a firm as a bundle of tangible (e.g. plant; buildings) and also intangible (e.g. patents; branding; collective culture) assets. Within this perspective, the organization's ability to acquire and deploy knowledge is an important intangible resource. So RBV puts a knowledge perspective on strategy centre stage $(21,22)$.

RBV argues firms have different resource profiles and capabilities so that they should be seen as heterogeneous. This variation accounts for their sustained and differential performance levels. Firms' resource profiles are imperfectly mobile and hence difficult for others to imitate - or even to understand - as they come in complex bundles. The effective use of its resources by a firm turns them into 'core competences' (23). Control over 'strategic resources' can give the firm sustained competitive advantage, where such resources are simultaneously: Valuable, Rare, difficult to Imitate by others and exploitable by the firm's Organizational processes (the so called VRIO model) (24).

Four key concepts within the RBV theoretical framework will next be briefly defined and discussed in relation to healthcare organizations, with a particular emphasis on KM.

\section{Key Resource-Based View (RBV) concepts}

1. Core (distinctive) competences

Core competences are key internal resources, which, when effectively developed and exploited, allow organizations to "spawn unanticipated products" and gain competitive advantage over their rivals (23). Bryson et al. (25) used the RBV concept of 'core competences' and (even more importantly) 'core distinctive competences' to inform a consultation process undertaken with a UK healthcare consulting unit to develop a modernised 'livelihood scheme' (i.e. a public sector version of a business model). The consultation exercise identified existing and developed distinctive competences (e.g. being well-networked in its field as a result of staff interaction over many years; deep sectoral knowledge) which could be better linked together in a self reinforcing bundle but also highlighted areas where new core competences needed to be developed. Core competences in this context can be seen as the collective learning in the consulting unit arising from the coordination of skills and networks.

\section{Dynamic Capabilities (DC)}

"Dynamic Capabilities" (DC) (26) is another concept central to RBV theory. There is not a single, agreed definition of DC, but the concept is usefully described by Eisenhardt and Martin (27) as "the organizational and strategic routines by which firms achieve new resource configurations as markets emerge, collide, split, evolve, and die". The DC concept adds to RBV theory by recognizing the role of the external environment in an organization's efforts to achieve sustain competitive advantage.

Casebeer et al. (28) explored reorganization in primary care organizations in Alberta, Canada, under conditions of financial constraint and strong performance management from a radically reforming provincial government introducing New Public Management reforms and reducing traditional expenditure levels. A RBV perspective could shed light on how such organizations (re) deployed internal resources so as to develop new processes and practices to improve their performance, under non-market conditions but now under severe expenditure pressure. The level of resource constraints in a public setting may mimic market volatility in the private ones. RBV does not then assume the existence of competitive market forces but can be usefully applied to the strategic behaviour of public services organizations that face performance challenges.

Casebeer et al. (28) were interested in the role of organizational learning - specifically what they termed 'learning as experimentation' - as a DC which helped these healthcare organizations cope with performance pressures, specifically as seen in six local experimental projects designed to upgrade primary care capacity and relieve pressure on the acute sector. How was the DC of 'learning as experimentation' fostered? Firstly, key individuals identified learning as a latent dynamic capability widely seen as legitimate by professionals 
in the healthcare field. Secondly, a leadership development strategy was adopted to build trust and participation widely across the system. Thirdly, there was a need for continual management of the tension between front line initiatives and central frameworks of control. So sustained developmental work was needed to grow and sustain this underpinning DC to enable improved system performance from transformed daily routines.

\section{Absorptive Capacity (AC)}

This concept refers to the process of knowledge transfer and application $(29,30)$, whereby firms recognize new, valuable and relevant knowledge, assimilate it into their processes and then apply it commercially. It is distinctive on putting corporate ' $\mathrm{KM}$ ' centre stage as a key resource that drives innovation.

Some UK healthcare organizations appear to perform badly in this domain. Harvey et al. (31) used the Absorptive Capacity (AC) concept to examine failing UK public services organizations, including in the healthcare sector, which were moving into crisis and which finally had change imposed on them from outside. These sites often failed to use information about their poor performance contained in publicly available external reports and continued to decline. There was little benchmarking with comparators or development of internal KM capacity. Their ability to explore and exploit new technological or scientific knowledge was compromised resulting in a reduced capacity and capability to innovate and transform their ailing situation.

\section{Organizational ambidexterity}

Raisch and Birkinshaw (32) define 'organizational ambidexterity' as 'an organization's ability to be aligned and efficient in the management of today's business demands while simultaneously being adaptive to changes in the environment'. As opposed to the conventional view of a trade-off between seeking resources beyond the firm and using resources within the firm, the ambidexterity premise argues firms capable of pursuing both exploitation and exploration at the same time outperform firms that focus on only one and indeed such ambidexterity is at the heart of effective dynamic capabilities.

We need more studies applying this concept to the healthcare domain. It might be explored in empirical research whether healthcare organizations operating in a highly performance managed system often over emphasise short term exploitation and neglect longer term and broader exploration or whether there are interesting exceptions to this proposition.

\section{Concluding discussion}

We suggest RBV usefully adds to existing perspectives on KM in healthcare organizations. It is first of all a well developed body of strategic management theory that can conceptually inform empirical studies to explore whether it is applicable or requires adaptation to the healthcare field. Secondly, it looks at organizational and system level competences rather than the more micro level focus of much existing KT literature. It is thirdly well suited to the study of mixed public/private organizational arenas now emerging (e.g.
Academic Health Sciences Networks in the UK, Veterans' Health Administration's Integrated Health and Research System in the US and in the Netherlands the Dutch Academic Collaborative Centres for Public Health) to support the wealth creation agenda evident in the UK health policy domain (4). Traditional models of strategy fit better in these mixed private/public arenas where there are more private firms. RBV may indeed be a highly appropriate model of strategy to employ in such a knowledge-based sector where the emphasis is on collective learning rather than market fit

Future RBV related research should examine empirically how healthcare organizations seek to develop the distinctive core competences, absorptive capacity, dynamic capabilities reviewed here and to preserve organizational ambidexterity. Will healthcare organizations migrate to their traditional specialisations, as the theory would predict, and away from a generalist profile? How do healthcare organizations acquire, process and use knowledge about their turbulent environments? How do knowledge intensive settings (such as Academic Health Science Centres) where the ability to transfer new scientific knowledge quickly into clinical practice speedily (33) is central to their mission seek to develop organization wide competences in this arena?

What are the managerial implications of a RBV perspective in healthcare organizations? It suggests a knowledge perspective is likely to be critical to their performance. It supports a move to specialisation - and building on traditional organizational strengths - as this profile is likely to provide rare and valuable knowledge difficult to imitate. It secondly raises the issue of organizational ambidexterity and suggests that some organizational slack may provide helpful headroom for protecting external search, innovation and long term growth. The theory suggests they need to invest in building underlying core competences over the long term, notably high absorptive capacity. This observation finally challenges the productivity or 'more for less' efficiency agenda operating in many healthcare systems in the current fiscal climate, or at least rebalances it.

\section{Acknowledgements}

This paper draws on sections of the final report of a project funded by the UK National Institute for Health Research Service Delivery and Organisation programme (project number 09/1002/13).

Ethical issues

Not applicable.

Competing interests

Authors declare that they have no competing interests.

Authors' contributions

All authors contributed equally to the production of this manuscript.

\section{Authors' affiliations}

${ }^{1}$ Department of Management, King's College London, London, UK. ${ }^{2}$ Crystal Blue Consulting Ltd., London, UK. ${ }^{3}$ School of Management, Royal Holloway University of London, Egham, Surrey, UK. ${ }^{4}$ Department of Management and Marketing, University of Melbourne, Melbourne, Australia. ${ }^{5}$ Independent Librarian, Kent, UK. ${ }^{6}$ Warwick Business School, University of Warwick, Coventry, UK. 


\section{References}

1. Burton CR, Rycroft-Malone J. Resource based view of the firm as a theoretical lens on the organisational consequences of quality improvement. Int J Health Policy Manag 2014; 3: 113-5. doi: 10.15171/ijhpm.2014.74

2. Rosenberg Hansen J, Ferlie E. Applying strategic management theories in public sector organizations: Developing a Typology. Public Management Review 2014 Sep. 17. doi: 10.1080/14719037.2014.957339

3. Cooksey Report. A Review of UK Health Research Funding. HM Treasury, London: HMSO: 2006.

4. Department of Health. Innovation, Health and Wealth. London: HMSO; 2011.

5. Sung NS, Crowley WF Jr, Genel M, Salber P, Sandy L, Sherwood $\mathrm{LM}$, et al. Central challenges facing the national clinical research enterprise. JAMA 2003; 289: 1278-87.

6. Lenfant C. Clinical Research to Clinical Practice - Lost in Translation? N Engl J Med 2003; 349: 868-74.

7. Quality Enhancement Research Initiative (QUERI) [home page on the internet]. [cited 14 Jan. 2015]. Available from: http://www. queri.research.va.gov/about/default.cfm

8. Graham ID, Tetroe J. Learning from the U.S. Department of Veterans Affairs Quality Enhancement Research Initiative: QUERI Series. Implement Sci 2009; 4: 13. doi: 10.1186/17485908-4-13

9. Institute for Healthcare Improvement [home page on the internet]. [cited 14 Jan. 2015]. Available from: http://www.ihi.org/ about/Pages/IHIVisionandValues.aspx

10. Berwick DM. Disseminating innovations in health care. JAMA 2003; 289: 1969-75.

11. Canadian Health Services Research Foundation. The Theory and Practice of Knowledge brokering in Canada's Health System. Ottawa, ON: Canadian Health Services Research Foundation; 2003. Available from: http://www.cfhi-fcass.ca/migrated/pdf/ Theory_and_Practice_e.pdf

12. Ward V, House A, Hamer S. Knowledge Brokering: The missing link in the evidence to action chain? Evid Policy 2009; 5: 267-79. doi: 10.1332/174426409X463811

13. Lomas J. Using Linkage And Exchange To Move Research Into Policy At A Canadian Foundation. Health Aff (Millwood) 2000; 19: $236-40$

14. Canadian Institutes of Health Research (CIHR). home page on the internet]. [cited 14 Jan. 2015]. Available from: http://www. cihr-irsc.gc.ca/e/13733.html

15. Graham ID, Tetroe JM. Getting evidence into policy and practice: perspective of a health research funder. J Can Acad Child Adolesc Psychiatry 2009; 18: 46-50.

16. Wehrens R, Bekker M, Bal R. Dutch Academic Collaborative Centres for Public Health: development through time-issues, dilemmas and coping strategies. Evid Policy 2012; 8: 149-70.

17. Straus S, Tetroe J, Graham I. Knowledge Translation in Health Care: Moving From Evidence to Practice. 2nd edition. Chichester:
Wiley Blackwell, BMJ Books: 2013.

18. Crilly, Tessa, Ashok Jashapara, Susan Trenholm, Anna Peckham, Graeme Currie, and Ewan Ferlie. "Research Utilization and Knowledge Mobilization By Health Care managers: Synthesising Evidence and Theory Using Perspectives of Organizational Form, Resource based View and Critical Theory." Final report. NIHR Service Delivery and Organisation programme; 2012. http://www.nets.nihr.ac.uk/_data/assets/pdf_file/0003/85107/ FR-09-1002-13.pdf

19. Penrose E. The Theory of the Growth of The Firm. New York: John Wiley; 1959

20. Wernerfelt B. A resource-based view of the firm. Strategic Management Journal 1984; 5: 171-80.

21. Spender J, Grant R. Knowledge and the Firm: Overview. Strategic Management Journal 1996; 17: 5-9.

22. Grant R. Towards a Knowledge based Theory of the Firm. Strategic Management Journal 1996; 17: 199-221.

23. Prahalad C, Hamel G. The Core Competence of the Corporation. Harv Bus Rev 1990; 68: 79-91.

24. Barney J, Clark D. Resource Based Theory: Creating and Sustaining Competitive Advantage. Oxford: Oxford University Press; 2007

25. Bryson J, Ackermann F, Eden C. Putting The Resource Based View of Strategy and Distinctive Competencies To Work in Public Organizations. Public Adm Rev 2007; 67: 702-17.

26. Teece D, Pisano G, Shuen A. Dynamic Capabilities and Strategic Management. Strategic Management Journal 1997; 18: 509-33.

27. Eisenhardt K, Martin J. Dynamic capabilities: What are they? Strategic Management Journal 2000; 21: 1105-21.

28. Casebeer A, Reay T, Deward J, Pablo A. Knowing Through Doing: Unleashing Latent Capabilities in the Public Sector. In: Walshe K, Harvey G, Jas P, editors. Connecting Knowledge and Performance in Public Services. Cambridge: Cambridge University Press; 2010. p. 251-75.

29. Cohen WM, Levinthal DA. Absorptive capacity: a new perspective on learning and innovation. Adm Sci Q 1990; 35: 128-52.

30. Bierly PE, Damanpour F, Santoro MD. The application of external knowledge: organizational conditions for exploration and exploitation. Journal of Management Studies 2009; 46: 481509.

31. Harvey G, Jas P, Walshe K, Skelcher C. Absorptive Capacity: How Organizations Assimilate and Apply Knowledge to Improve Performance. In: Walshe K, Harvey G, Jas P, editors. Connecting Knowledge and Performance in Public Services. Cambridge: Cambridge University Press; 2010. p. 226-50.

32. Raisch S, Birkinshaw J. Organizational ambidexterity: Antecedents, outcomes, and moderators. J Manage 2008; 34: 375-409.

33. Fischer MD, Ferlie E, French C, Fulop N, Wolfe C. The Creation and Survival of an Academic Health Science Organization: Counter-Colonization Through A New Organizational Form? University of Oxford-Said Business School Working Paper; 2013. 